\title{
Heart Failure-Induced Diaphragm Myopathy
}

\author{
Aline Regina Ruiz Lima ${ }^{a}$ Paula Felippe Martinez ${ }^{b}$ Ricardo Luiz Damatto ${ }^{a}$ \\ Marcelo Diarcadia Mariano Cezar ${ }^{\mathrm{a}}$ Daniele Mendes Guizonia Camila Bonomo ${ }^{\mathrm{a}}$ \\ Silvio Assis Oliveira Jr ${ }^{b}$ Maeli Dal-Pai Silva ${ }^{c}$ Leonardo Antonio Mamede Zornoffa \\ Katashi Okoshia Marina Politi Okoshia
}

Internal Medicine Department, Botucatu Medical School - UNESP, Botocutu; ${ }^{b}$ Biological Sciences and Health Center, Federal University of Mato Grosso do Sul - UFMS, Campo Grande, MS, 'Department of Morphology, Biosciences Institute - UNESP, Botucatu, SP, Brazil

\section{Key Words}

Skeletal muscle - MAPK - Myogenic regulatory factors - Myosin heavy chain isoforms • Echocardiography $\bullet$ Myocardial infarction

\begin{abstract}
Background: Intracellular signaling pathways involved in skeletal myosin heavy chain $(\mathrm{MyHC})$ isoform alterations during heart failure (HF) are not completely understood. We tested the hypothesis that diaphragm expression of mitogen-activated protein kinases (MAPK) and myogenic regulatory factors is changed in rats with myocardial infarction (MI) induced HF. Methods: Six months after MI rats were subjected to transthoracic echocardiography. After euthanasia, infarcted rats were subdivided in MI/HF- group (with no HF evidence; $\mathrm{n}=10$ ), and $\mathrm{MI} / \mathrm{HF}+$ (with right ventricular hypertrophy and lung congestion; $n=10)$. Sham-operated rats were used as controls $(n=10)$. MyHC isoforms were analyzed by electrophoresis. Statistical analysis: ANOVA and Pearson correlation. Results: MI/HF- had left cardiac chambers dilation with systolic and diastolic left ventricular dysfunction. Cardiac injury was more intense in MI/HF+ than MI/HF-. MyHC I isoform percentage was higher in MI/HF+ than MI/HF-, and IIb isoform lower in MI/HF+ than Sham. Left atrial diameter-to-body weight ratio positively correlated with MyHC I $(p=0.005)$ and negatively correlated with MyHC IIb $(p=0.02)$. TNF- $\alpha$ serum concentration positively correlated with MyHC I isoform. Total and phosphorylated ERK was lower in MI/ HF- and MI/HF+ than Sham. Phosphorylated JNK was lower in MI/HF- than Sham. JNK and p38 did not differ between groups. Expression of NF- $\mathrm{KB}$ and the myogenic regulatory factors MyoD, myogenin, and MRF4 was similar between groups. Conclusion: Diaphragm $\mathrm{MyHC}$ fast-to-slow shift is related to cardiac dysfunction severity and TNF- $\alpha$ serum levels in infarcted rats. Reduced ERK expression seems to participate in $\mathrm{MyHC}$ isoform changes. Myogenic regulatory factors and NF-KB do not modulate diaphragm MyHC distribution during chronic HF.
\end{abstract}

Copyright $@ 2014$ S. Karger AG, Basel 
Lima et al.: Heart Failure-Induced Myopathy

\section{Introduction}

Chronic heart failure (HF) is characterized by a decreased exercise capacity with early fatigue and dyspnea. Respiratory and peripheral muscle abnormalities have been observed during experimental and clinical HF and may be involved in exercise intolerance [1-7]. Several morphological, biochemical, enzymatic, and functional alterations have been described in respiratory muscles [8-12]. Respiratory muscle dysfunction is commonly observed in $\mathrm{HF}$ patients and is related to disease severity [13-17]. A shift in myosin heavy chain (MyHC) isoforms from MyHC II to MyHC I, often described in clinical and experimental studies, can contribute to diaphragm dysfunction and characterizes a muscle change towards slow fiber phenotype $[4,10,12,18,19]$. However, molecular mechanisms involved in MyHC abnormalities during HF have not been fully established.

Different intracellular pathways regulate skeletal muscle MyHC expression. The mitogenactivated protein kinase (MAPK) family consists of at least four members: extracellular signal-regulated kinase 1/2 (ERK 1/2), p38 MAPK, c-Jun NH2-terminal kinase (JNK), and ERK5 [20]. MAPK signaling, especially the ERK 1/2 pathway, is necessary for skeletal muscle mass and phenotype maintenance [20,21]. In vitro studies have shown that inhibition of this signaling cascade increases slow-twitch fiber-specific proteins and reduces fast-twitch fiber characteristics, inducing the slow muscle fiber phenotype program [20, 21]. MAPKs can be modulated by several factors; these include inflammatory cytokines, particularly TNF- $\alpha[22,23]$, and oxidative stress [24], which are increased during HF. JNK is a key protein in mediating TNF- $\alpha$-induced IGF-I resistance and muscle differentiation suppression [22]. Similar to JNK, p38 can be modulated by TNF- $\alpha$ in a dose dependent manner [25]. MAPKs are also involved in regulating myogenic regulatory factors (MRF) $[25,26]$. Despite the essential role of the MAPK pathway on myogenesis, we have not identified any studies evaluating the relationship between MAPK expression and diaphragm changes during HF.

MRF MyoD, myogenin, and MRF4 modulate muscle protein expression by regulating myogenic cell activation, proliferation, and differentiation $[27,28]$. MyoD and myogenin act in fast or slow muscular fiber phenotype conservation, and MRF4 in muscle mass maintenance [27]. Despite the importance of MRFs in skeletal muscular phenotype maintenance, few studies have examined their expression during HF. In peripheral muscle, we observed that muscle atrophy and necrosis were combined with increased MyoD gene expression and reduced myogenin protein levels [29]. In rat diaphragm, decreased MyHC II isoforms were associated with reduced MyoD gene expression [12]. Finally, it should be pointed out that TNF- $\alpha$ can also activate nuclear factor (NF)- $\kappa B$, which decreases MyoD gene expression and MyHCs synthesis [30].

In this study, we tested the hypothesis that expression of MAPKs and MFR is changed in HF-induced diaphragm myopathy. We therefore evaluated diaphragm phenotype and MAPKs and MRF expression in rats with myocardial infarction-induced heart failure. As skeletal muscle alterations can also occur during compensated cardiac remodeling [31, 32], we analyzed diaphragm muscle of infarcted rats during both compensated left ventricular dysfunction and clinical HF.

\section{Materials and Methods}

\section{Experimental groups}

All experiments and procedures were approved by the Animal Experimentation Ethics Committee of Botucatu Medical School, UNESP, SP, Brazil, which follows the guidelines established by the Brazilian College for Animal Experimentation (Protocol number 646). Male Wistar rats (200-250 g) were purchased from the Central Animal House, Botucatu Medical School, UNESP. Myocardial infarction (MI) was induced by anterior descending coronary artery ligation according to a previously described method [33, 34]. Rats were anesthetized with ketamine $(60 \mathrm{mg} / \mathrm{kg})$ and subjected to left lateral thoracotomy. After heart exteriorization, the left atrium was retracted to facilitate left coronary artery ligation with 5-0 mononylon 
Lima et al.: Heart Failure-Induced Myopathy

between the pulmonary outflow tract and the left atrium. The heart was then replaced in the thorax, the lungs inflated by positive pressure, and the thoracotomy closed. Sham-operated rats were used as controls $(\mathrm{n}=10)$. All animals were housed in a temperature controlled room at $23{ }^{\circ} \mathrm{C}$ and kept on a 12-hour light/ dark cycle. Food and water were supplied ad libitum.

Six months after inducing MI, rats were subjected to transthoracic echocardiography and euthanized the next day. At the time of euthanasia, we determined the presence or absence of congestive HF by assessing lung congestion (lung weight/body weight ratio $>2$ standard deviations above Sham group mean) and right ventricular hypertrophy (right ventricle weight-to-body weight ratio greater than $0.8 \mathrm{mg} / \mathrm{g}$ ) [34-36]. After euthanasia, the infarcted rats were subdivided in two groups: 1 ) MI/HF- rats with no evidence of HF ( $n=10)$, and 2) MI/HF+ rats with right ventricular hypertrophy and lung congestion ( $n=10)$.

\section{Echocardiography}

Echocardiographic evaluation was performed using a commercially available echocardiograph (General Electric Medical Systems, Vivid S6, Tirat Carmel, Israel) equipped with a 5-11.5 MHz multifrequency probe, as previously described [37-40]. Rats were anesthetized by intramuscular injection of a mixture of ketamine $(50 \mathrm{mg} / \mathrm{kg})$ and xylazine $(0.5 \mathrm{mg} / \mathrm{kg})$. A two-dimensional parasternal short-axis view of the left ventricle (LV) was obtained at the level of the papillary muscles. M-mode tracings were obtained from short-axis views of the LV at or just below the tip of the mitral-valve leaflets, and at the level of the aortic valve and left atrium. M-mode images of the LV were printed on a black-and-white thermal printer (Sony UP-890MD) at a sweep speed of $100 \mathrm{~mm} / \mathrm{s}$. All LV structures were manually measured by the same observer. Values obtained were the mean of at least five cardiac cycles on M-mode tracings. The following structural variables were measured: left atrium diameter (LA), LV diastolic and systolic diameters (LVDD and LVSD, respectively), and LV diastolic posterior wall thickness (PWT). Left ventricular function was assessed by the following parameters: endocardial fractional shortening (FS), posterior wall shortening velocity (PWSV), early and late diastolic mitral inflow velocities (E and $\mathrm{A}$ waves), E/A ratio, and E-wave deceleration time (EDT).

\section{Morphological analysis}

At euthanasia, rats were weighed and anesthetized with intraperitoneal sodium pentobarbital (50 $\mathrm{mg} / \mathrm{kg}$ ). Hearts were removed by thoracotomy and the atria and ventricles were separated and weighed. Right and left costal diaphragm portions were dissected, weighed, immediately frozen in liquid nitrogen, and stored at $-80^{\circ} \mathrm{C}$.

Infarct size was measured by left ventricle histological analysis in hematoxylin and eosin stained sections according to a previously described method [34]. Infarct size was calculated by dividing the sum of endocardial and epicardial ventricular lengths of the infarcted area by the sum of the total endocardial and epicardial ventricular circumferences. Measurements were acquired from midventricular slices (5-6 mm from the apex), under the assumption that the left midventricular slice shows a close linear relation with the sum of the measurements from all heart slices.

Transverse sections approximately 8-10 $\mu \mathrm{m}$ thick of the frozen diaphragm muscle were cut in a cryostat at $-20^{\circ} \mathrm{C}$ and stained with hematoxylin and eosin. Muscle trophicity was assessed by measuring at least 200 cross-sectional fiber areas from each muscle. To evaluate diaphragm muscle fibers according to metabolism activity, sections were submitted to NADH-tetrazolium reductase (TR) reaction. Slides were incubated in $\mathrm{NADH}$ and nitro blue tetrazolium solution diluted in Tris buffer $0.2 \mathrm{M}(\mathrm{pH} 7.4)$, for $40 \mathrm{~min}$ at $37^{\circ} \mathrm{C}$, washed in distillated water, and fixed in formol buffer $5 \%$ (pH 7.0). Sections were then submitted to dehydration and mounting protocol. Measurements were performed using a compound LEICA DM LS microscope attached to a computerized imaging analysis system (Media Cybernetics, Silver Spring, Maryland, USA).

\section{Real time RT-PCR analysis}

Total RNA was extracted from diaphragm muscle with TRIzol Reagent (Invitrogen Life Technologies, Carlsbad, CA, USA) according to a previously described method [41, 42]. Frozen muscles were mechanically homogenized on ice in $1 \mathrm{ml}$ of ice-cold TRIzol reagent. Total RNA was solubilized in RNase-free $\mathrm{H}_{2} \mathrm{O}$, incubated in DNase I (Invitrogen Life Technologies) to remove any DNA in the sample, and quantified by measuring optical density (OD) at $260 \mathrm{~nm}$. RNA purity was ensured by obtaining a $260 / 280 \mathrm{~nm}$ OD ratio of approximately 2.0. One microgram of RNA was reverse transcribed using High Capacity cDNA Reverse Transcription Kit in a total volume of $20 \mu \mathrm{L}$, according to standard methods (Applied Biosystems, Foster 
Lima et al.: Heart Failure-Induced Myopathy

City, CA, EUA). Aliquots of $2.5 \mu \mathrm{L}$ (10-100 ng) of cDNA were then submitted to real-time PCR reaction using $10 \mu \mathrm{L} 2 \mathrm{X}$ TaqMan ${ }^{\circledast}$ Universal PCR Master Mix (Applied Biosystems) and $1 \mu \mathrm{L}$ of customized assay (20X) containing sense and antisense primers and Taqman (Applied Biosystems, Foster City, CA, EUA) probe specific to each gene, myogenin (Taqman assay Rn00567418_m1; Ref. seq. Genbank NM_ 017115), MyoD (Taqman assay Rn00598571_m1; Ref. seq. Genbank NM_176079) and MRF4 (Taqman assay Rn00565920_ m1; Ref. seq. Genbank NM_013172). Amplification and analysis were performed using Step One Plus ${ }^{\mathrm{TM}}$ Real Time PCR System (Applied Biosystems, Foster City, CA, EUA), according to manufacturer recommendations. Expression data were normalized to $\beta$-actin (reference gene; Taqman assay Rn00667869_m1; Ref. seq. Genbank NM_031144.2) expression. Reactions were performed in triplicate and expression levels calculated using the $\mathrm{C}_{\mathrm{T}}$ comparative method $\left(2^{-\Delta \Delta C \mathrm{~T}}\right)$.

Myosin heavy chain (MyHC) isoforms

MyHC isoform analysis was performed in duplicate by sodium dodecyl sulfate polyacrylamide gel electrophoresis (SDS-PAGE) [29, 43]. Frozen samples of diaphragm muscle (100 mg) were mechanically homogenized on ice in $0.8 \mathrm{~mL}$ of protein extraction solution containing $50 \mathrm{mM}$ phosphate potassium buffer (pH 7.0), $0.3 \mathrm{M}$ sucrose, $0.5 \mathrm{mM}$ dithiotreitol (DTT), $1 \mathrm{mM}$ ethylenediaminetetracetic acid (EDTA), $0.3 \mathrm{mM}$ phenylmetylsulphonyl fluoride (PMSF), $10 \mathrm{mM}$ sodium fluoride, and protease inhibitor cocktail (Sigma, St. Louis, MO, USA). Homogenates were centrifuged at $12,000 \mathrm{~g}$ at $4{ }^{\circ} \mathrm{C}$ for $20 \mathrm{~min}$ to remove insoluble tissue. Total protein quantification was performed in supernatant aliquots by the Bradford method. Samples were then diluted to a final concentration of $1 \mu \mathrm{g}$ of protein $/ \mu \mathrm{L}$ in a solution containing $65 \%$ (vol/vol) glycerol, $2.5 \%$ (vol/vol) 2-mercaptoethanol, $1.15 \%$ (wt/vol) SDS, and $0.45 \%$ (wt/vol) Tris-HCl (pH 6.8). Small amounts of the diluted extracts $(10 \mu \mathrm{L})$ were loaded onto a 7-10\% SDS-PAGE separating gel with a $4 \%$ stacking gel, run overnight (13 hours) at $275 \mathrm{~V}$, and stained with Coomassie blue. Four MyHC isoforms, MyHC I, MyHC IIb, MyHC IId/IIx, and MyHC IIa were identified according to molecular mass and quantified by densitometry. Their relative quantity was expressed as a percentage of total myosin heavy chain.

\section{Western blotting analysis}

Diaphragm protein levels were analyzed by Western blot according to a previously described method $[36,44]$ using specific anti- myogenin (myogenin M-225 sc-576), MyoD (MyoD M-318 sc-760), MRF4 (Myf6 C-19 sc-301), JNK (JNK 1/2 D-9 sc-137019), p-JNK (p-JNK G-7 sc-6254), p38 (p38 $\alpha / \beta$ A-12 sc-7972), p-p38 ( p-p38 Thr 180/Tyr 182-R sc-17852-R), ERK (ERK 1 C-16 sc-93), p-ERK (p-ERK 1/2 Thr 202/Tyr

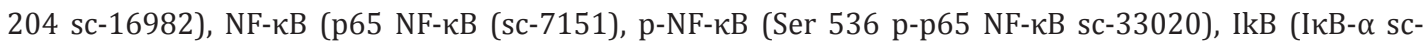
1643), and p-IkB (p-IкB- $\alpha$ sc-101713) antibodies (Santa Cruz Biotechnology, Santa Cruz, CA, USA). Protein levels were normalized to GAPDH (6C5 sc-32233, Santa Cruz Biotechnology). Samples were separated on polyacrylamide gel and then transferred to a nitrocellulose membrane. After blockage, the membrane was incubated with the primary antibodies overnight at $4{ }^{\circ} \mathrm{C}$. The membrane was then washed with PBS and Tween 20 and incubated with secondary peroxidase-conjugated antibodies for 90 minutes at room temperature. ECL Western Blotting Substrate (Pierce Protein Research Products, Rockford, USA) was used to detect bound antibodies. Membrane was then stripped (Restore Western Blot Stripping Buffer, Pierce Protein Research Products, Rockford, USA) to remove previous antibody. After blockage, membrane was incubated with anti-GAPDH antibody.

\section{Circulating TNF- $\alpha$ and IL-6}

As MRF expression and MAPK pathway can be modulated by cytokines, we assessed TNF- $\alpha$ and interleukin (IL)-6 serum concentration by enzyme linked immunosorbent assay (ELISA) using ELISA rat TNF- $\alpha$ ultra-sensitive and IL-6 kits (BioSource International, Camarillo, CA, USA). The procedures were performed according to manufacturer instructions.

\section{Statistical analysis}

Data are expressed as mean \pm standard deviation. Comparisons between groups were performed by one-way analysis of variance (ANOVA) followed by the Tukey test. The Student's $t$-test was used to compare $\mathrm{MI}$ size between MI/HF- and MI/HF+ groups. Association between MyHC isoforms and left atrium diameterto-body weight ratio or TNF- $\alpha$ serum concentration was assessed by calculating the Pearson correlation coefficient. The level of significance was set at $5 \%$. 
Lima et al.: Heart Failure-Induced Myopathy

Table 1. Body weight, heart weight, and pulmonary and systemic congestion data

\begin{tabular}{lcccc}
\hline & $\begin{array}{c}\text { Sham } \\
(\mathrm{n}=10)\end{array}$ & $\begin{array}{c}\text { MI/HF- } \\
(\mathrm{n}=10)\end{array}$ & $\begin{array}{c}\text { MI/HF+ } \\
(\mathrm{n}=10)\end{array}$ & p value \\
\hline BW (g) & $461 \pm 40$ & $495 \pm 38$ & $463 \pm 36$ & 0.092 \\
LVW (g) & $0.764 \pm 0.072$ & $0.897 \pm 0.090^{*}$ & $0.881 \pm 0.080^{*}$ & $<0.001$ \\
RVW (g) & $0.202 \pm 0.015$ & $0.248 \pm 0.030^{*}$ & $0.483 \pm 0.054^{*} \#$ & $<0.001$ \\
Atria (g) & $0.090 \pm 0.016$ & $0.131 \pm 0.026^{*}$ & $0.288 \pm 0.055^{*} \#$ & $<0.001$ \\
LV/BW (mg/g) & $1.723 \pm 0.012$ & $1.830 \pm 0.136^{*}$ & $1.856 \pm 0.174^{*}$ & $<0.001$ \\
RV/BW (mg/g) & $0.441 \pm 0.039$ & $0.501 \pm 0.055^{*}$ & $1.045 \pm 0.109^{*} \#$ & $<0.001$ \\
Atria/BW (mg/g) & $0.197 \pm 0.040$ & $0.266 \pm 0.052^{*}$ & $0.625 \pm 0.132^{*} \#$ & $<0.001$ \\
Lung (g) & $1.879 \pm 0.251$ & $1.968 \pm 0.190$ & $3.464 \pm 0.364^{*} \#$ & $<0.001$ \\
Lung/BW (mg/g) & $4.082 \pm 0.447$ & $3.979 \pm 0.286$ & $7.528 \pm 1.041^{*} \#$ & $<0.001$ \\
\hline
\end{tabular}

MI/HF-: myocardial infarction without heart failure; MI/HF+: myocardial infarction with heart failure; n: number of animals; BW: body weight; LVW: left ventricle weight; RVW: right ventricle weight. Data are mean $\pm \mathrm{SD} ;{ }^{*}$ vs Sham; \# vs MI/HF-; ANOVA and Tukey.

Table 2. Cardiac structural and left ventricular functional parameters

\begin{tabular}{|c|c|c|c|c|}
\hline & $\begin{array}{l}\text { Sham } \\
(n=10)\end{array}$ & $\begin{array}{l}\text { MI/HF- } \\
(n=10)\end{array}$ & $\begin{array}{c}\mathrm{MI} / \mathrm{HF}+ \\
(\mathrm{n}=10)\end{array}$ & $\mathrm{p}$ value \\
\hline LVDD (mm) & $8.44 \pm 0.41$ & $10.88 \pm 0.99^{*}$ & $12.02 \pm 0.53^{*} \#$ & $<0.001$ \\
\hline LVDD $/ \mathrm{BW}(\mathrm{mm} / \mathrm{kg})$ & $17.71 \pm 1.22$ & $21.02 \pm 1.813^{*}$ & $25.51 \pm 1.96^{*} \#$ & $<0.001$ \\
\hline $\operatorname{LVSD}(\mathrm{mm})$ & $4.41 \pm 0.32$ & $8.48 \pm 1.32^{*}$ & $10.1 \pm 0.51^{*}$ & $<0.001$ \\
\hline LVDPWT (mm) & $1.47 \pm 0.07$ & $1.58 \pm 0.13$ & $1.73 \pm 0.19^{*}$ & $<0.001$ \\
\hline $\mathrm{LA}(\mathrm{mm})$ & $6.0 \pm 0.4$ & $6.7 \pm 0.7^{*}$ & $8.8 \pm 0.9 * \#$ & $<0.001$ \\
\hline $\mathrm{LA} / \mathrm{BW}(\mathrm{mm} / \mathrm{kg})$ & $12.47 \pm 0.92$ & $13.11 \pm 1.53$ & $18.68 \pm 2.10^{*} \#$ & $<0.001$ \\
\hline HR (bpm) & $279 \pm 10$ & $274 \pm 39$ & $260 \pm 32$ & 0.348 \\
\hline FS (\%) & $47.8 \pm 2.5$ & $22.4 \pm 6.6^{*}$ & $16.3 \pm 3.5^{*} \#$ & $<0.001$ \\
\hline PWSV $(\mathrm{mm} / \mathrm{s})$ & $37.8 \pm 2.5$ & $28.3 \pm 6.6^{*}$ & $22.1 \pm 3.5^{*} \#$ & $<0.001$ \\
\hline E-wave & $66.9 \pm 3.9$ & $66.1 \pm 9.7$ & $89.5 \pm 15.1 * \#$ & $<0.001$ \\
\hline A-wave & $42.8 \pm 7.2$ & $49.3 \pm 12.8$ & $23.4 \pm 18.1^{*} \#$ & $<0.001$ \\
\hline $\mathrm{E} / \mathrm{A}$ & $1.60 \pm 0.26$ & $1.42 \pm 0.37$ & $4.96 \pm 1.90^{*} \#$ & 0.002 \\
\hline EDT (ms) & $45.3 \pm 4.4$ & $52.0 \pm 6.7^{*}$ & $32.7 \pm 5.5^{*} \#$ & $<0.001$ \\
\hline EF & $0.87 \pm 0.02$ & $0.61 \pm 0.10^{*}$ & $0.50 \pm 0.10^{*}$ & $<0.001$ \\
\hline \multicolumn{5}{|c|}{$\begin{array}{l}\text { MI/HF-: myocardial infarction without heart failure; MI/HF+: myocardial infarction with heart failure; n: number of } \\
\text { animals; LVDD and LVSD: left ventricular (LV) diastolic and systolic dimension, respectively; BW: body weight; } \\
\text { LVDPWT: LV diastolic posterior wall thickness; LA: left atrium dimension. HR: heart rate; bpm: beats per minute; FS: } \\
\text { endocardial fractional shortening; PWSV: posterior wall shortening velocity; E-wave and A-wave: early and late } \\
\text { diastolic mitral inflow, respectively; EDT: E wave deceleration time; EF: ejection fraction. Data are mean } \pm \text { SD; * vs } \\
\text { Sham; \# vs MI/HF-; ANOVA and Tukey. }\end{array}$} \\
\hline
\end{tabular}

\section{Results}

\section{General characteristics of rats}

Anatomical data are shown in Table 1. Body weight (BW) did not differ between groups. Left ventricle weight (LVW) and LVW/BW ratio were higher in both MI groups than in the Sham group; there was no difference between MI/HF- and MI/HF+. Right ventricle weight (RVW), atria weight, and RVW/BW and atria/BW ratios were greater in the MI/ $\mathrm{HF}-$ and MI/HF+ groups than in Sham and greater in MI/HF+ than in MI/HF-. Lung weight and lung weight/BW ratio were higher in MI/HF+ than Sham and MI/HF-. Right ventricular hypertrophy and pulmonary congestion were observed in all rats from $\mathrm{MI} / \mathrm{HF}+$; no animal from MI/HF- or Sham presented these alterations.

Infarcted area did not differ between MI groups (MI/HF-: $39.5 \pm 6.9 \%$; MI/HF+: $40.8 \pm$ $12.5 \%$ of the total left ventricle area; $\mathrm{p}=0.79$ ).

\section{Echocardiographic evaluation}

Table 2 shows cardiac structural parameters and LV functional data. LV diastolic diameter (LVDD), LVDD/BW ratio, and left atrium diameter (LA) were higher in MI/HF- and $\mathrm{MI} / \mathrm{HF}+$ than Sham and greater in MI/HF+ than MI/HF-. LV systolic diameter (LVSD) was higher in both MI/HF- and MI/HF+ than Sham. LV diastolic posterior wall thickness was higher in $\mathrm{MI} / \mathrm{HF}+$ than Sham. LA/BW ratio was significantly higher in MI/HF+ than Sham and MI/HF-. Heart rate did not differ between groups. Endocardial fractional shortening and 
Fig. 1. Diaphragm fibers cross-sectional area according to metabolism activity. MI/HF-: myocardial infarction without heart failure; MI/HF+: myocardial infarction with heart failure; $n$ : number of animals. Data are expressed as mean \pm standard deviation; Anova $(\mathrm{p}=0.48)$.

Fig. 2. Diaphragm myosin heavy chain (MyHC) expressed as percentage of total MyHC analyzed by SDS-PAGE electroforesis. MI/HF-: myocardial infarction without heart failure; $\mathrm{MI} / \mathrm{HF}+$ : myocardial infarction with heart failure; $n$ : number of animals. Data are expressed as mean \pm standard deviation; ${ }^{*} \mathrm{p}<0.05$ vs Sham; \# p<0.05 vs MI/HF-. Anova and Tukey.
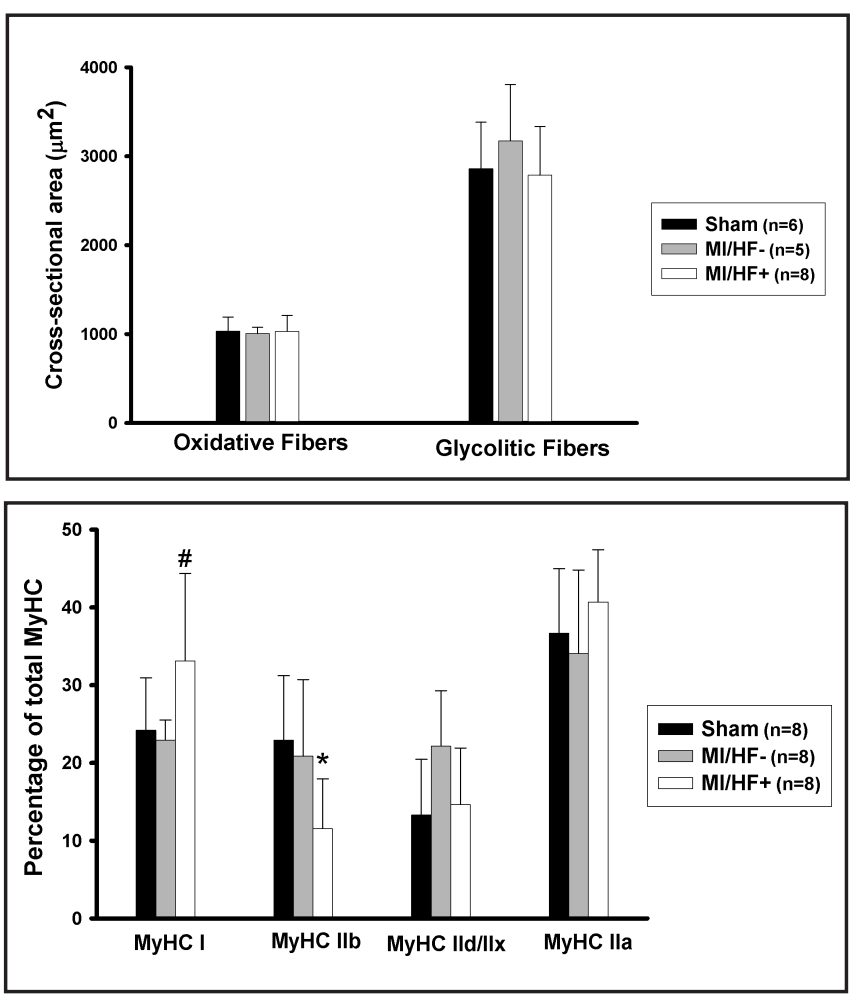

Table 3. The myogenic regulatory factors MyoD, MRF4, and myogenin gene and protein expression

\begin{tabular}{lcccc}
\hline & $\begin{array}{c}\text { Sham } \\
(\mathrm{n}=10)\end{array}$ & $\begin{array}{c}\text { MI/HF- } \\
(\mathrm{n}=10)\end{array}$ & $\begin{array}{c}\text { MI/HF+ } \\
(\mathrm{n}=10)\end{array}$ & $\mathrm{p}$ value \\
\hline $\begin{array}{l}\text { Gene expression } \\
\text { MyoD/ } \beta \text {-actin }\end{array}$ & $1.00 \pm 0.70$ & $0.92 \pm 0.89$ & $0.59 \pm 0.38$ & 0.39 \\
MRF4/ $\beta$-actin & $1.00 \pm 0.33$ & $1.37 \pm 0.84$ & $1.00 \pm 0.57$ & 0.52 \\
Myogenin/ $\beta$-actin & $1.00 \pm 1.59$ & $0.73 \pm 0.62$ & $0.75 \pm 0.56$ & 0.81 \\
Protein Expression & & & & \\
MyoD/GAPDH & $1.00 \pm 0.71$ & $0.76 \pm 0.17$ & $1.22 \pm 0.77$ & 0.33 \\
MRF4/GAPDH & $1.00 \pm 0.24$ & $1.03 \pm 0.22$ & $0.98 \pm 0.22$ & 0.93 \\
Myogenin/GAPDH & $1.00 \pm 0.09$ & $0.99 \pm 0.24$ & $1.08 \pm 0.36$ & 0.79 \\
\hline
\end{tabular}

MI/HF-: myocardial infarction without heart failure; MI/HF+: myocardial infarction with heart failure; n: number animals. Data are mean \pm SD (arbitrary units); ANOVA and Tukey.

posterior wall shortening velocity were lower in MI groups than Sham and lower in MI/ $\mathrm{HF}+$ than MI/HF-. Mitral A wave was lower and mitral $\mathrm{E}$ wave and $\mathrm{E} / \mathrm{A}$ ratio higher in MI/ $\mathrm{HF}+$ than Sham and MI/HF-. E wave deceleration time was lower in MI/HF+ than the other groups and higher in MI/HF- than Sham.

\section{Morphological and biochemical analysis}

General diaphragm muscle morphology was similar between groups. Diaphragm fiber cross-sectional areas were not statistically different between groups (Sham 1,354 \pm 170 ; MI/HF- 1,522 \pm 397 ; MI/HF $+1,477 \pm 241 \mu \mathrm{m}^{2} ; \mathrm{p}=0.53$ ). NADH-TR histochemical reaction allowed us to differentiate muscle fibers according to their predominant metabolism into oxidative or glycolitic fibers. There was no difference in oxidative or glycolitic fiber crosssectional areas between groups ( $\mathrm{p}=0.48$; Fig. 1 ).

Myosin heavy chain (MyHC) isoforms

The percentage of MyHC I was greater in MI/HF+ than MI/HF- (Sham $24.2 \pm 6.8$; MI/ HF- $22.9 \pm 2.6$; MI/HF+ $33.1 \pm 11.2 \%$; p=0.04; Fig. 2). Isoform IIb percentage was lower in MI/HF+ than Sham (Sham $22.9 \pm 8.3$; MI/HF- $20.9 \pm 9.9$; MI/HF+ $11.5 \pm 6.4 \%$; p=0.03). 
Fig. 3. Pearson correlation between left atrium diameter-to-body weight ratio (LA/ $\mathrm{BW}$ ) and myosin heavy chain (MyHC) isoform I $(\mathrm{r}=0.626 ; \mathrm{p}=0.005)$ and IIb ( $\mathrm{r}=-0.539$; $\mathrm{p}=0.021$ ). MI/HF-: myocardial infarction without heart failure; $\mathrm{MI} / \mathrm{HF}+$ : myocardial infarction with heart failure; n: number of animals.

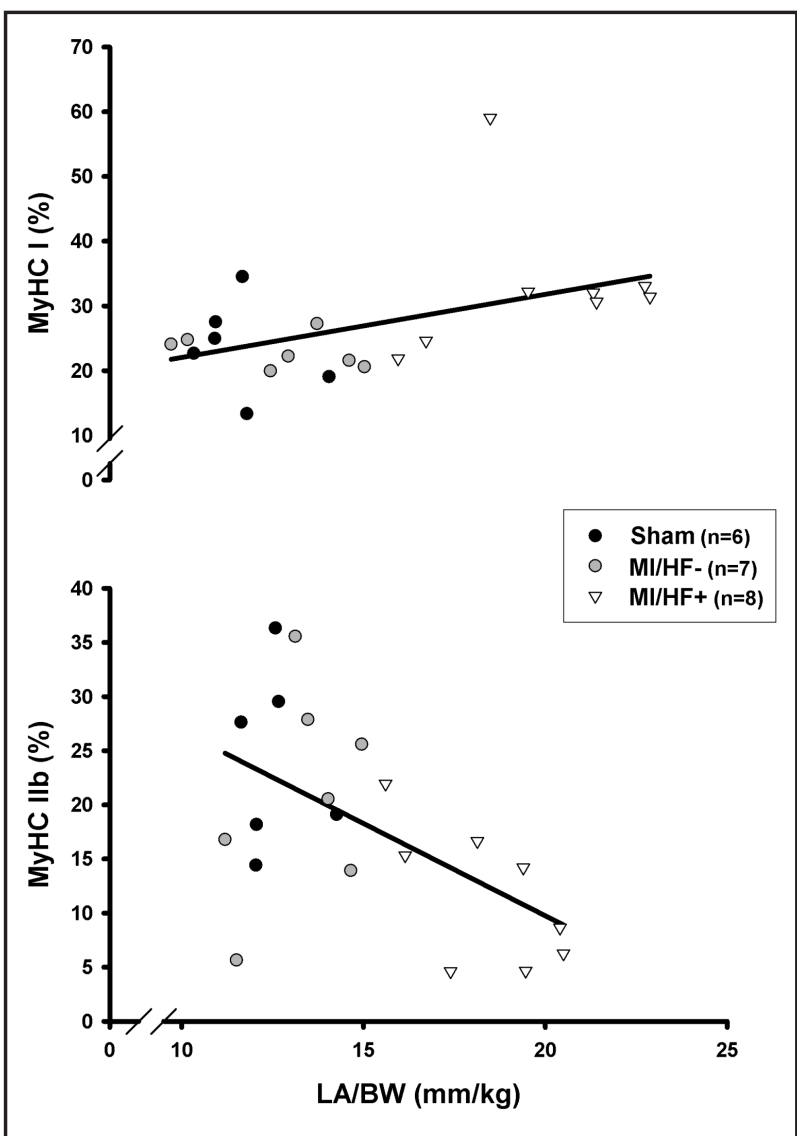

MyHC IId/IIx (Sham $13.3 \pm 7.2$; MI/HF- $22.2 \pm 7.1$; MI/HF+ $14.6 \pm 7.3 \%$; $=0.074$ ) and IIa (Sham $36.7 \pm 8.3$; MI/HF- $4.1 \pm 10.7$; MI/HF+ $40.7 \pm 6.7 \%$; $\mathrm{p}=0.34$ ) isoforms did not differ between groups. Pearson's coefficient was calculated to evaluate whether MyHC isoforms were related to heart failure severity, using left atrium diameter normalized to BW and MyHC isoform percentages. LA/BW was positively correlated to MyHC I isoform percentage $(\mathrm{p}=0.005)$ and negatively correlated to MyHC IIb isoform ( $p=0.02$; Fig. 3).

Western blotting and real time RT-PCR analysis

Myogenic regulatory factors gene and protein expression did not differ between groups (Table 3). MAPK protein levels are presented in Fig. 4. Total and phosphorylated ERK were lower in both MI groups than Sham. The p-ERK/ERK ratio did not differ between groups (Sham 1.00 \pm 0.35 ; MI/HF- $0.69 \pm 0.27$; MI/HF+ 0.75 \pm 0.24 arbitrary units; $\mathrm{p}=0.11$ ). Total JNK and total and phosphorylated p38 did not differ between groups. Phosphorylated JNK/ GAPDH and p-JNK/JNK (Sham 1.00 \pm 0.40 ; MI/HF- 0.49 \pm 0.37 ; MI/HF+ 0.75 \pm 0.31 arbitrary units; $p=0.049$ ) ratios were lower in MI/HF- than Sham. NF- $\kappa B$ and IkB expression did

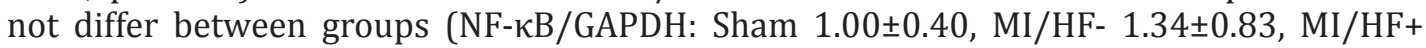
$0.86 \pm 0.29, \mathrm{p}=0.28 ; \mathrm{p}-\mathrm{NF} \kappa \mathrm{B} / \mathrm{GAPDH}$ : Sham 1.00 $\pm 0.45, \mathrm{MI} / \mathrm{HF}-1.16 \pm 1.01, \mathrm{MI} / \mathrm{HF}+0.99 \pm 0.62$, $\mathrm{p}=0.89$; IkB/GAPDH: Sham 1.00 $\pm 0.44, \mathrm{MI} / \mathrm{HF}-0.77 \pm 0.73, \mathrm{MI} / \mathrm{HF}+0.75 \pm 0.90, \mathrm{p}=0.17$; pIkB / GAPDH: Sham 1.00 \pm 0.29 , MI/HF- $1.51 \pm 0.40, \mathrm{MI} / \mathrm{HF}+1.03 \pm 0.51$ arbitrary units, $\mathrm{p}=0.09$ ).

\section{Circulating TNF- $\alpha$ and $I L-6$}

TNF- $\alpha$ and IL-6 serum concentrations were higher in MI/HF+ than Sham. Cytokine levels In MI/HF- were between those of Sham and MI/HF+ groups and did not differ from either group (Fig. 5). TNF- $\alpha$ serum concentration positively correlated with MyHC I isoform percentage ( $\mathrm{p}=0.032$; Fig. 6$)$. 
Fig. 4. Protein levels of mitogen-actived protein kinase analyzed by Western blotting. Protein levels were normalized to GAPDH levels. MI/ HF-: myocardial infarction without heart failure; MI/ $\mathrm{HF}+$ : myocardial infarction with heart failure; n: number of animals. Data are expressed as mean \pm standard deviation; *p<0.05 vs Sham; Anova and Tukey.

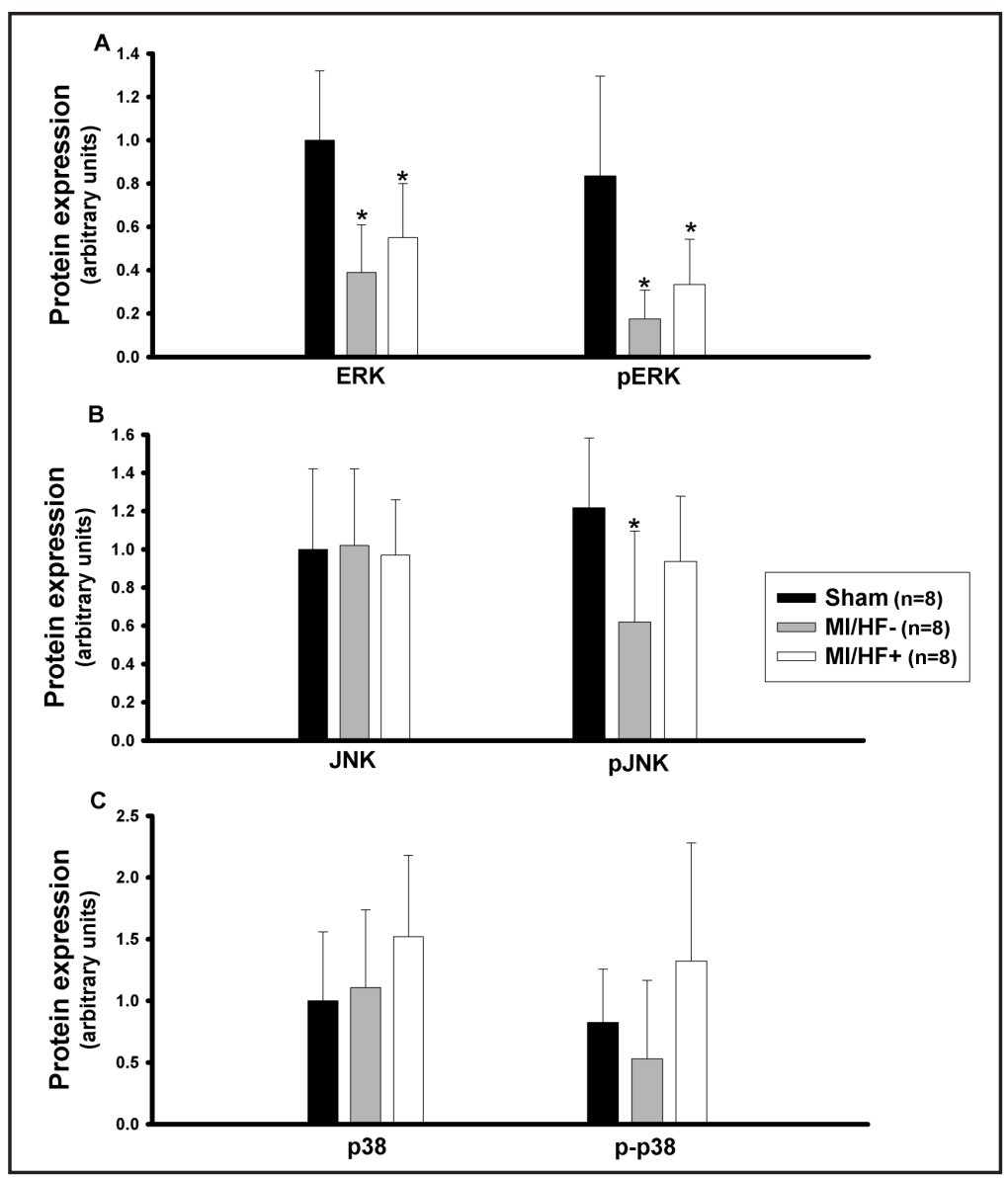

Fig. 5. Tumor necrosis factor-alpha (TNF- $\alpha$; A) and interleukin (IL)-6 (B) serum concentration measured by ELISA. MI/HF-: myocardial infarction without heart failure; $\mathrm{MI} / \mathrm{HF}+$ : myocardial infarction with heart failure; n: number of animals. Data are expressed as mean \pm standard deviation; * $\mathrm{p}<0.05$ vs Sham; Anova and Tukey.

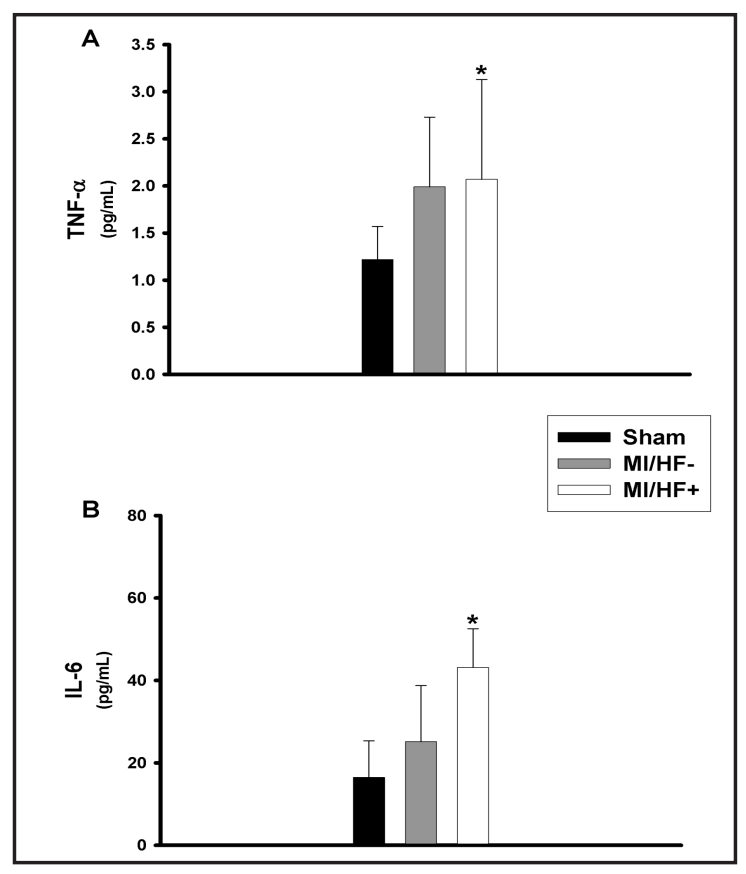

\section{Discussion}

In this study, we evaluated expression of mitogen-activated protein kinases and myogenic regulatory factors, myosin heavy chain isoforms, and muscle trophicity in the 
Fig. 6. Pearson correlation between tumor necrosis factor (TNF)- $\alpha$ serum levels and myosin heavy chain (MyHC) isoform I percentage. Sham: $n=6$; MI/HF-: myocardial infarction without heart failure $(n=7)$; $\mathrm{MI} / \mathrm{HF}+$ : myocardial infarction with heart failure $(n=8)$.

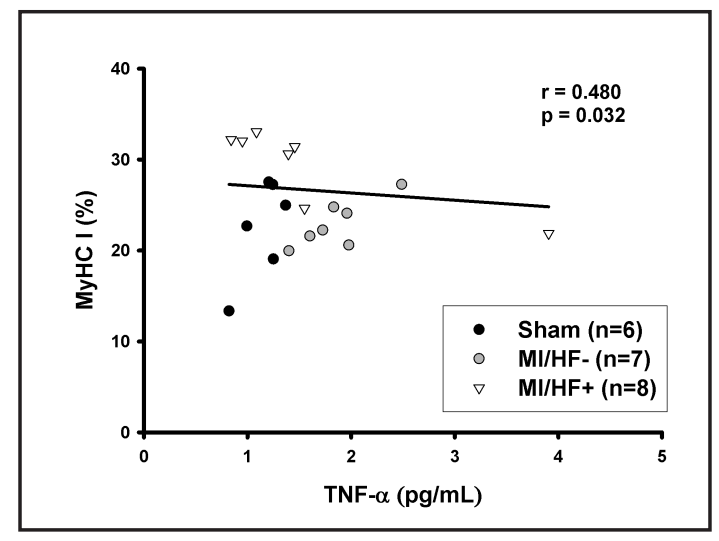

diaphragm of infarcted rats during both compensated left ventricular dysfunction and heart failure.

Experimental myocardial infarction has often been used for inducing HF. This model has the advantage of slow HF development, usually observed in clinical settings [34]. Cardiac remodeling was characterized by evaluating cardiac structures and left ventricular function by transthoracic echocardiography. The MI/HF- group had left cardiac chambers dilation with systolic and diastolic left ventricular dysfunction compared to the Sham group. Despite similar infarction size, left chamber dilation and left ventricular dysfunction were more intense in MI/HF+ than MI/HF-. Diastolic dysfunction was severe in MI/HF+, with a restrictive pattern, characterized by increased E/A ratio and reduced $\mathrm{E}$ wave deceleration time. As left atrium diameter highly correlates with left ventricular systolic and diastolic function in rats [34, 45], left atrium diameter-to-body weight ratio was used as a severity marker for ventricular dysfunction. In MI/HF+, HF was characterized by right ventricular hypertrophy and lung congestion.

The diaphragm is the most important inspiratory muscle in mammals. In this study, diaphragm cross sectional area did not differ between groups for both oxidative and glycolytic fibers; this is in agreement with previous studies $[9,12]$. Experimental studies have suggested that proinflammatory cytokine activation in HF, such as TNF- $\alpha$ and IL-6, can lead to skeletal muscle atrophy $[46,47]$. However, as the diaphragm usually experiences increased work to expand congested lungs in HF, it is probable that these antagonistic factors have contributed to preserved muscle trophicity.

$\mathrm{MI} / \mathrm{HF}+$ presented increased MyHC isoform I percentage compared to MI/HF-, and reduced MyHC IIb isoform compared to Sham. The change in MyHC distribution towards a slower muscle phenotype has been attributed to the work overload the muscle is subjected to during HF $[4,9,19]$. In this study, we showed for the first time that an alteration in diaphragm MyHC isoforms is related to cardiac dysfunction severity. Considering results from the three groups, MyHC I isoform positively correlated and MyHC IIb negatively correlated with left atrium diameter-to-body weight ratio. Furthermore, MyHC I isoform positively correlated with TNF- $\alpha$ serum levels.

TNF- $\alpha$ modulates diaphragm strength and MyHC distribution [48, 49]. Increased TNF- $\alpha$ serum levels, induced by genetic manipulation or exogenous administration, change myofibril protein synthesis and reduce diaphragm strength $[48,49]$. In contrast, TNF- $\alpha$ deletion in dystrophic mouse muscle improves diaphragm strength [50].

We evaluated myogenic regulatory factors and the MAPKs and NF- $\kappa \mathrm{B}$ pathways as potential intracellular signaling pathways involved in HF-induced diaphragm MyHC isoform changes. To the best of our knowledge, this is the first study to evaluate MAPK and NF- $\mathrm{KB}$ expression in diaphragm muscle during both phase compensated cardiac dysfunction and HF.

MAPKs are activated by several stimuli and are essential for many cellular functions [51]. The ERK $1 / 2$ pathway, but not p38 or JNK, is preferentially activated in fast-twitch 
muscles. ERK 1/2 inhibition decreased fast fiber-specific gene and protein expression, and induced the slow muscle fiber phenotype program in vitro and in vivo [20]. In our study, the decrease of ERK1/2 was also combined with reduced fast type IIb MyHC and increased slow type I MyHC isoform in MI/HF+.

MAPKs expression in skeletal muscle under different experimental conditions is not completely understood. For instance, ERK 1/2 was stimulated in the diaphragm of rats subjected to increased inspiratory pressure [23] and in skeletal muscle cell culture submitted to hypoxia [52]. In contrast, ERK phosphorylation was decreased in skeletal muscle of rats with sepsis [53]. ERK 1/2 signalling has been associated with IGF-1-mediated protein synthesis in skeletal muscle [54]. Considering that growth hormone and IGF1 signalling is blunted during HF $[55,56]$, inhibited ERK signalling could be expected, as observed in this study. ERK inhibition may also have occurred due to dual specificity MAPK phosphatases (MKP) activity [51]. MKPs dephosphorylate and inactivate ERK, JNK, and p38, acting as endogenous controls of MAPKs $[21,51,57]$ and MKPs, particularly MKP-1, seem to modulate MyHC expression in skeletal muscle [21]. MKPs can be activated by several factors found during cardiac remodeling and HF development, such as increased oxidative stress and cytokines levels [51]; this could explain the reduced ERK levels in both infarcted groups. The reduced ERK expression in MI/HF- suggests that diaphragm molecular changes can occur early during the cardiac remodelling process, not just in decompensated HF. In fact, we have previously shown that MyHC isoform alterations occur early during chronic pressure overload in rat soleus muscle [31].

Although decreased in both MI groups, phosphorylated JNK protein levels were only statistically lower in MI/HF- compared to Sham. As ERK, JNK phosphorylation can also be inhibited by MKPs [51]. However, as JNK activation is sustained by chronic TNF- $\alpha$ stimulation [58], the increased TNF- $\alpha$ levels in MI/HF+ could have acted to preserve JNK in this group.

TNF- $\alpha$ induces IkB phosphorylation and degradation, allowing NF- $\kappa B$ to translocate to nucleus, decreasing MyoD expression and MyHC synthesis [30]. In this study, heart failure did not change NF- $\mathrm{KB}$ or IkB protein expression in diaphragm muscle, suggesting that this pathway is not involved in diaphragm myopathy.

Although there is substantial evidence that myogenic regulatory factors are changed in HF-induced skeletal myopathy $[12,29,36]$, our hypothesis that MRFs modulate MyHC isoforms distribution in diaphragm was not confirmed. Myogenin is frequently found in association with oxidative enzyme expression and seems to play a role in skeletal metabolism characterization $[27,28,59]$. In this study, despite a diaphragm muscle shift towards a slower pattern, myogenin expression was not changed, suggesting that it is not involved in MyHC isoform distribution. MRF4 is predominantly expressed in slow oxidative fibers and seems to play a role in regulating muscular trophism [60]. In our study, unchanged MRF expression is in accordance with preserved diaphragm cross sectional fiber area. In acute HF, MyoD mRNA was reduced in diaphragm muscle [12]. MyoD is usually increased during stem cell proliferation [61], which is usually associated to muscle injury and regeneration [62]. Thus, the absence of diaphragm morphological changes could justify the preservation of MyoD expression in the infarcted rats.

In conclusion, the fast-to-slow shift in diaphragm myosin heavy chain isoforms is related to left ventricular dysfunction severity and TNF- $\alpha$ serum levels in rats with myocardial infarction. Reduced ERK expression seems to participate in the myosin heavy chain isoform change. Myogenic regulatory factors and NF- $\kappa \mathrm{B}$ pathway do not modulate myosin heavy chain distribution in diaphragm muscle during chronic heart failure.

\section{Acknowledgements}

We are grateful to Jose Carlos Georgette and Mario Batista Bruno for their technical assistance and Colin Edward Knaggs for English editing. Financial support was provided by CNPq (306857/2012-0 and 306845/2012-1) and FAPESP (2007/57499-6; 2010/50084-8; 2008/58655-4). 
Lima et al.: Heart Failure-Induced Myopathy

\section{References}

1 Harrington D, Anker SD, Coats AJS: Preservation of exercise capacity and lack of peripheral changes in asymptomatic patients with severely impaired left ventricular function. Eur Heart J 2001;22:392-399.

-2 Anker SD, Ponikowski PP, Clark AL, Leyva F, Rauchhaus M, Kemp M, Teixeira MM, Hellewell PG, Hooper J, Poole-Wilson PA, Coats AJS: Cytokines and neurohormones relating to body composition alterations in the wasting syndrome of chronic heart failure. Eur Heart J 1999;20:683-693.

-3 Strassburg S, Springer J, Anker SD: Muscle wasting in cardiac cachexia. Intern J Biochem Cell Biol 2005;37:1938-1947.

4 Tikunov BA, Mancini D, Levine S: Changes in myofibrillar protein composition of human diaphragm elicited by congestive heart failure. J Mol Cell Cardiol 1996;28:2537-2541.

5 MacFarlane NG, Darnley GM, Smith GL: Cellular basis for contractile dysfunction in the diaphragm from a rabbit infarct model of heart failure. Am J Physiol Cell Physiol 2000;278:C739-C746.

-6 Lima ARR, Martinez PF, Okoshi K, Guizoni DM, Zornoff LAM, Campos DHS, Oliveira Jr SA, Bonomo C, Dal Pai-Silva M, Okoshi MP: Myostatin and follistatin expression in skeletal muscles of rats with chronic heart failure. Int J Exp Path 2010;91:54-62.

7 Von Haehling S, Steinbeck L, Doehner W, Springer J, Anker SD: Muscle wasting in heart failure: An overview. Int J Biochem Cell Biol 2013;45:2257-2265.

-8 van Hees HWH, van der Heijden HFM, Hafmans T, Ennen L, Heunks LMA, Verheugt FWA, Dekhuijzen PNR: Impaired isotonic contractility and structural abnormalities in the diaphragm of congestive heart failure rats. Int J Cardiol 2008;128:326-335.

-9 Lindsay DC, Lovegrove CA, Dunn MJ, Bennett JG, Pepper JR, Yacoub MH, Poole-Wilson PA: Histological abnormalities of muscle from limb, thorax and diaphragm in chronic heart failure. Eur Heart J 1996, 17:1239-1250.

10 De Sousa E, Veksler V, Bigard X, Mateo P, Serrurier B, Ventura-Clapier R: Dual influence of disease and increased load on diaphragm muscle in heart failure. J Mol Cell Cardiol 2001;33:699-710.

11 van Hees HWH, van der Heijden HFM, Ottenheijm CA, Heunks LMA, Pigmans CJ, Verheugt FWA, Brouwer RM, Dekhuijzen PNR: Diaphragm single-fiber weakness and loss of myosin in congestive heart failure rats. Am J Physiol Heart Circ Physiol 2007;293:H819-H828.

12 Lopes FS, Carvalho RF, Campos GER, Sugizaki MM, Padovani CR, Nogueira CR, Cicogna AC, Dal Pai-Silva M: Down-regulation of MyoD gene expression in rat diaphragm muscle with heart failure. Int J Exp Path 2008;89:216-22.

13 Mancini DM, Henson D, LaManca J, Levine S: Evidence of reduced respiratory muscle endurance in patients with heart failure. J Am Coll Cardiol 1994;24:972-81.

14 Ambrosino N, Opasich C, Crotti P, Cobelli F, Tavazzi L, Rampulla C: Breathing pattern, ventilatory drive and respiratory muscle strenght in patients with chronic heart failure. Eur Respir J 1994;7:17-22.

15 Habedank D, Meyer FJ, Hetzer R, Anker SD, Ewert R: Relation of respiratory muscle strenght, cachexia and survival in severe heart failure. J Cachexia Sarcopenia Muscle 2013;4:277-285.

16 Marco E, Ramirez-Sarmineto AL, Coloma A, Sartor M, Comin-Colet J, Vila J, Enjuanes C, Bruguera J, Escalada F, Gea J, Orozco-Levi M: High-intensity vs. sham inspiratory muscle training in patients with chronic heart failure: a prospective randomized trial. Eur J Heart Fail 2013;15:892-901.

17 Dall'Ago P, Chiappa GRS, Guths H, Stein R, Ribeiro JP: Inspiratory muscle training in patients with heart failure and inspiratory muscle weakness. A randomized trial. J Am Coll Cardiol 2006; 47:757-763.

18 Tikunov B, Levine S, Mancini D: Chronic congestive heart failure elicits adaptations of endurance exercise in diaphragmatic muscle. Circulation 1997;95:910-916.

19 Howell S, Maarek JMI, Fournier M, Sullivan K, Zhan WZ, Sieck GC: Congestive heart failure: differential adaptation of the diaphragm and latissimus dorsi. J Appl Physiol 1995;79:389-397.

20 Shi H, Scheffler JM, Pleitner JM, Zeng L, Park S, Hannon KM, Grant AL, Gerrard DE: Modulation of skeletal muscle fiber type by mitogen activated protein kinase signaling. FASEB J 2008;22:2990-3000.

21 Shi H, Scheffler JM, Zeng C, Pleitner JM, Hannon KM, Grant AL: Mitogen-activated protein kinase signaling is necessary for the maintenance of skeletal muscle mass. Am J Physiol Cell Physiol 2009;296:C1040-C1048.

22 Strle K, Broussard SR, McCusker RH, Shen W-H, LeCleir JM, Johnson RW, Freund GG, Dantzer R, Kelley KW: C-jun N-terminal kinase mediates tumor necrosis factor-alpha suppression of differentiation in myoblasts. Endocrinology 2006;147:4363-4373. 
Lima et al.: Heart Failure-Induced Myopathy

23 Sigala I, Zacharatos P, Toumpanakis D, Michailidou T, Noussia O, Theocharis S, Roussos C, Papapetropoulos A, Vassilakopoulos T: MAPKs and NF-kB differentially regulate cytokine expression in the diaphragm in response to resistive breathing: the role of oxidative stress Am J Physiol Regul Integr Comp Physiol 2011;300:R1152-R1162.

24 Yoshizumi M, Abe J, Haendeler J, Huang Q, Berk BC: Src and Cas mediate JNK activation but not ERK1/2 and p38 kinases by reactive oxygen species. J Biol Chem 2000;275:11706-11712.

25 Chen S-E, Jin B, Li Y-P: TNF-alpha regulates myogenesis and muscle regeneration by activating p38 MAPK. Am J Physiol Cell Physiol 2007;292:C1660-1671.

-26 Lluis F, Perdiguero E, Nebreda AR, Cánoves-Muñoz P: Regulation of skeletal mucsle gene expression by p38 MAP kinase. Trends Cell Bilogy 2006;16:36-44.

-27 Hughes SM, Taylor JM, Tapscott SJ, Gurley CM, Carter WJ, Peterson CA: Selective accumulation of MyoD and myogenin mRNAs in fast and slow muscle is controlled by innervation and hormones. Development 1993;118:1137-1147.

28 Hughes SM, Chi MM-Y, Lowry OH, Gundersen K: Myogenin induces a shift of enzyme activity from glycolytic to oxidative metabolism in muscles of transgenic mice. J Cell Biol 1999;145:633-642.

29 Martinez PF, Okoshi K, Zornoff LAM, Carvalho RF, Oliveira Jr SA, Lima ARR, Campos DHS, Damatto RL, Nogueira CR, Dal Pai-Silva M, Okoshi MP: Chronic heart failure-induced skeletal muscle atrophy, necrosis, and myogenic regulatory factors changes. Med Sci Monit 2010;16:BR374-383.

30 Acharyya S, Ladner KJ, Nelsen LL, Damrauer J, Reiser PJ, Swoap S, Guttridge DC: Cancer cachexia is regulated by selective targeting of skeletal muscle gene products. J Clin Invest 2004;114:370-378.

31 Carvalho RF, Cicogna AC, Campos GER, Assis JMF, Padovani CR, Okoshi MP, Dal Pai-Silva M: Myosin heavy chain expression and atrophy in rat skeletal muscle during transition from cardiac hypertrophy to heart failure. Int J Exp Path 2003;84:201-206.

-32 Coirault C, Langeron O, Lambert F, Blanc F, Lerebours G, Claude N, Riou B, Chemla D, Lecarpentier Y: Impaired skeletal muscle performance in the early stage of cardiac pressure overload in rabbits: beneficial effects of angiotensin-converting enzyme inhibition. J Pharmacol Exp Ther 1999;291:70-75.

-33 Minicucci MF, Azevedo PS, Martinez PF, Lima ARR, Bonomo C, Guizoni DM, Polegato BF, Okoshi MP, Okoshi K, Matsubara BB, Paiva SAR, Zornoff LAM: Critical infarct size to induce ventricular remodeling, cardiac dysfunction and heart failure in rats. Int J Cardiol 2011;51:242-243.

-34 Martinez PF, Okoshi K, Zornoff LAM, Oliveira Jr SA, Campos DHS, Lima ARR, Damatto RL, Cezar MDM, Bonomo C, Guizoni DM, Padovani CR, Cicogna AC, Okoshi MP: Echocardiographic detection of congestive heart failure in postinfarction rats. J Appl Physiol 2011;111:543-551.

-35 Cicogna AC, Robinson KG, Conrad CH, Singh K, Squire R, Okoshi MP, Bing OHL: Direct effects of colchicine on myocardial function. Studies in hypertrophied and failing spontaneously hypertensive rats. Hypertension 1999;33:60-65.

-36 Damatto RL, Martinez PF, Lima AR, Cezar MD, Campos DH, Oliveira Junior SA, Guizoni DM, Bonomo C, Nakatani BT, Dal Pai Silva M, Carvalho RF, Okoshi K, Okoshi MP: Heart failure-induced skeletal myopathy in spontaneously hypertensive rats. Int J Cardiol 2013;167:698-703.

-37 Okoshi K, Ribeiro HB, Okoshi MP, Matsubara BB, Gonçalves G, Barros R, Cicogna AC: Improved systolic ventricular function with normal myocardial mechanics in compensated cardiac hypertrophy. Jpn Heart J 2004;45:647-656.

38 Okoshi K, Fioretto JR, Okoshi MP, Cicogna AC, Aragon FF, Matsubara LS, Matsubara BB: Food restriction induces in vivo ventricular dysfunction in spontaneously hypertensive rats without impairment of in vitro myocardial contractility. Braz J Med Biol Res 2004;37:607-613.

39 Sugizaki MM, Carvalho RF, Aragon FF, Padovani CR, Okoshi K, Okoshi MP, Zanati SG, Pai-Silva MD, Novelli EL, Cicogna AC: Myocardial dysfunction induced by food restriction is related to morphological damage in normotensive middle-aged rats. J Biomed Sci 2005;12:641-649.

40 Nascimento AF, Luvizotto RA, Leopoldo AS, Lima-Leopoldo AP, Seiva FR, Justulin LAJ, Silva MD, Okoshi $\mathrm{K}$, Wang XD, Cicogna AC: Long-term high-fat diet-induced obesity decreases the cardiac leptin receptor withou apparent lipotoxicity. Life Sci 2011;88:1031-1038.

-41 Rosa CM, Xavier NP, Campos DH, Fernandes AA, Cezar MD, Martinez PF, Cicogna AC, Gimenes C, Gimenes R, Okoshi MP, Okoshi K: Diabetes mellitus activated fetal gene program and intensifies cardiac remodeling and oxidative stress in aged spontaneously hypertensive rats. Cardiovasc Diabetol 2013;12:152. 


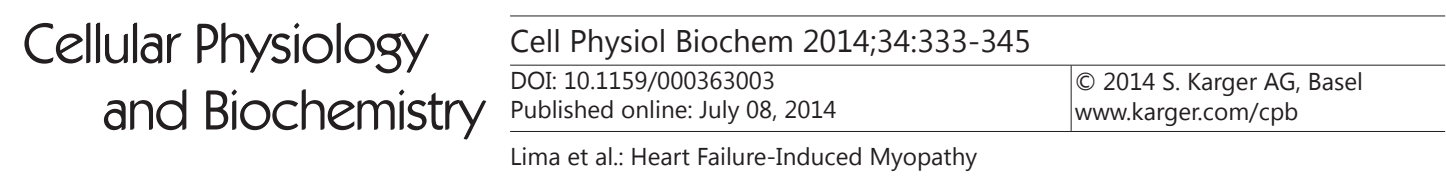

42 Cezar MDM, Damatto RL, Martinez PF, Lima ARR, Campos DHS, Rosa CM, Guizoni DM, Bonomo C, Cicogna AC, Gimenes R, Pagan LU, Okoshi MP, Okoshi K: Aldosterone blockade reduces mortality without changing cardiac remodeling in spontaneously hypertensive rats. Cell Physiol Biochem 2013;32:1275-1287.

43 Oliveira Jr SA, Dal Pai Silva M, Martinez PF, Lima-Leopoldo AP, Campos DH, Leopoldo AS, Okoshi MP, Okoshi K, Padovani CR, Cicogna AC: Diet-induced obesity causes metabolic, endocrine and cardiac alterations in spontaneously hypertensive rats. Med Sci Monit 2010;16:BR367-BR373.

44 Yan X, Schuldt AJ, Price RL, Amende I, Liu FF, Okoshi K, Ho KK, Pope AJ, Borg TK, Lorell BH, Morgan JP: Pressure overload-induced hypertrophy in transgenic mice selectively overexpressing AT2 receptors in ventricular myocytes. Am J Physiol Heart Circ Physiol 2008;294:1274-1281.

45 Sjaastad I, Sejersted OM, Ilebekk A, Bjornerheim R: Echocardiographic criteria for detection of postinfarction congestive heart failure in rats. J Appl Physiol 2000;89:1445-1454.

$\checkmark 46$ Janssen SP, Gayan-Ramirez G, Van den Bergh A, Herijgers P, Maes K, Verbeken E, Decramer M: Interleukin-6 causes myocardial failure and skeletal muscle atrophy in rats. Circulation 2005;111:996-1005.

47 Argiles JM, Busquets S, Lopez-Soriano FJ: The pivotal role of cytokines in muscle wasting during cancer. Int J Biochem Cell Biol 2005;37:2036-2046.

48 Cheema IR, Hermann C, Postell S, Barnes P: Effect of chronic excess of tumour necrosis factor-alpha on contractile proteins in rat skeletal muscle. Cytobios 2000;103:169-176.

49 Li X, Moody MR, Engel D, Walker S, Clubb FJ, Sivasubramanian N, Mann DL, Reid MB: Cardiac-specific overexpression of tumor necrosis factor-alfa causes oxidative stress and contractile dysfunction in mouse diaphragm. Circulation 2000;102:1690-1696.

50 Gosselin LE, Barkley JE, Spencer MJ, McCormick KM, Farkas GA: Ventilatory dysfunction in mdx mice: impact of tumor necrosis factor-alpha deletion. Muscle Nerve 2003;28:336-343.

51 Camps M, Nichols A, Arkinstall S: Dual specificity phosphatases: a gene family for control of MAP kinase function. FASEB J 1999;14:6-16.

-52 Osorio-Fuentealba C, Valdés JA, Riquelme D, Hidalgo J, Hidalgo C, Carrasco MA: Hypoxia stimulates via separate pathways ERK phosphorylation and NF-kappaB activation in skeletal muscle cells in primary culture. J Appl Physiol 2009;106:1301-1310.

53 Vary TC, Deiter G, Lang CH: Diminished ERK 1/2 and p38 MAPK phosphorylation in skeletal muscle during sepsis. Shock 2004;22:548-554.

54 Haddad F, Adams GR: Inhibition of MAP/ERK kinase prevents IGF-1 induced hypertrophy in rat muscles. J Appl Physiol 2004;96:203-210.

55 Toth MJ, Ades PA, LeWinter MM, Tracy RP, Tchernof A: Skeletal muscle myofibrillar mRNA expression in heart failure: relationship to local and circulating hormones. J Appl Physiol 2006;100:35-41.

-56 Anker SD, Volterrani M, Pflaum CD, Strasburger CJ, Osterziel KJ, Doehner W, Ranke MB, Poole-Wilson PA, Giustina A, Dietz R, Coats AJS: Acquired growth hormone resistance in patients with chronic heart failure: implications for therapy with growth hormone. J Am Coll Cardiol 2001;38:443-452.

57 Wu JJ, Roth RJ, Anderson EJ, Hong EG, Lee MK, Choi CS, Neufer PD, Shulman GI, Kim JK, Bennett AM: Mice lacking MAP kinase phosphatase-1 have enhanced MAP kinase activity and resistance to diet-induced obesity. Cell Metab 2006;4:61-73.

-58 Jamaluddin M, Wang S, Boldogh I, Tian B, Brasier AR: TNF-alpha-induced NF-kappaB/RelA Ser276 phosphorylation and enhanceosome formation is mediated by an ROS-dependente PKAc pathway. Cell Signal 2007;19:1419-1433.

59 Ekmark M, Gronevik E, Schjerling P, Gundersen K: Myogenin induces higher oxidative capacity in preexisting mouse muscle fibres after somatic DNA transfer. J Physiol 2003;548:259-269.

60 Loughna PT, Brownson C: Two myogenic regulatory factor transcripts exhibit muscle-specific responses to disuse and passive stretch in adult rats. FEBS Letter 1996;390:304-306.

61 Smith CK, Janney MJ, Allen RE: Temporal expression of myogenic regulatory genes during activation, proliferation, and differentiation of rat skeletal muscle satellite cells. J Cell Physiol 1994;159:379-385.

62 Chargé SBP, Rudnicki MA: Cellular and molecular of muscle regeneration. Physiol Rev 2004;84:209-238. 